\title{
Pathways to Reducing Poverty and Sharing Prosperity in India
}

\author{
Schemes to Systems: \\ Lessons from Social Protection in India
}


๑ 2019 International Bank for Reconstruction and Development/The World Bank 1818 H Street NW

Washington DC 20433

Telephone: 202-473-1000

Internet: www.worldbank.org

This work is a product of the staff of The World Bank with external contributions. The findings, interpretations, and conclusions expressed in this work do not necessarily reflect the views of The World Bank, its Board of Executive Directors, or the governments they represent.

The World Bank does not guarantee the accuracy of the data included in this work. The boundaries, colors, denominations, and other information shown on any map in this work do not imply any judgment on the part of The World Bank concerning the legal status of any territory or the endorsement or acceptance of such boundaries.

\section{Rights and Permissions}

The material in this work is subject to copyright. Because The World Bank encourages dissemination of its knowledge, this work may be reproduced, in whole or in part, for noncommercial purposes as long as full attribution to this work is given.

Any queries on rights and licenses, including subsidiary rights, should be addressed to World Bank Publications, The World Bank Group, 1818 H Street NW, Washington, DC 20433, USA; fax: 202-522-2625; e-mail:pubrights@worldbank.org. 


\title{
Pathways to Reducing Poverty and Sharing Prosperity in India
}

\author{
Schemes to Systems: \\ Lessons from Social Protection in India
}




\section{ABSTRACT}

The changing nature of work is upending traditional employment globally, and with it, social protection systems. As countries like India aspire to grow further and navigate a phase of rapid economic transformation, investments in social protection programs are critical to ensure broad gains for societies in general, and the poorest in particular. The following series of articles take stock of India's major social protection programs, including pension programs, health insurance, the Public Distribution System and the Mahatma Gandhi National Rural Employment Guarantee Scheme. The latter two are among the largest anti-poverty measures in India and indeed the world, while the former are relatively new instruments for unorganized workers. However, these programs are important for India's future social policy architecture as they attempt to de-link social security benefits from a person's place of work. The final two articles draw on experiences from the past decade to highlight how best to use information technology to strengthen the capability of governments to design and implement social protection programs.

\section{ACKNOWLEDGEMENTS}

This series of articles was prepared by a team led by Shrayana Bhattacharya, John Blomquist and Rinku Murgai. The team of authors thanks Vanita Leah Falcao, Andrew Fraker, Seth Garz, Nandini Gupta, Avantika Prabhakar, and Amit Sharma for research support. The team also thanks Junaid Ahmad, Michal Rutkowski, Stefano Paternostro, Pablo Gottrett, Jorge Coarasa, Philip 0 Keefe, Nandita Roy and Martin Rama for their valuable comments and insights. Finally, we thank Indian Express and Hindustan Times for partnering with us in disseminating this research to their readers. Authors can be contacted at: sbhattacharya3@worldbank.org 


\section{CONTENTS}

1. Schemes to Systems 1

2. Poverty to Vulnerability 4

3. The Future of Social Protection $\quad 7$

4. Taking Stock of Core Social Protection Interventions in India 10

$\begin{array}{ll}\text { 4.1 Pensions and Ageing } & 10\end{array}$

4.2 Health Insurance $\quad 12$

$\begin{array}{ll}\text { 4.3 Public Distribution System } & 14\end{array}$

$\begin{array}{ll}\text { 4.4 MGNREGS } & 17\end{array}$

5. Technology, State Capability and Social Protection 20

$\begin{array}{ll}\text { 5.1 The Solutions State } & 20\end{array}$

5.2 The Learning State 23

$\begin{array}{lr}\text { Author Bios } & 26\end{array}$

$\begin{array}{ll}\text { Statistical Appendix } & 30\end{array}$ 



\section{SCHEMES TO SYSTEMS}

\section{The Future of Social Protection in India}

\section{Junaid Ahmad}

Between 1997 and 2017, India's per capita national income increased more than four-fold. The pace of poverty reduction also accelerated, with a similar three-to four-fold increase in the rate of poverty decline after 2000 . To progress further, India needs to create a large, productive and healthy middle-class. This requires sustained expansion of good jobs, human capital and equal opportunities. While India faces an exceptional task due to its continent-like-size and diversity, it doesn't have to tackle challenges posed by pursuing fast-paced economic transformation in isolation.

International experience holds important insights, particularly on how strong social protection systems can support the growth process. Most G20 countries have increased expenditures on social protection as they grow. Why? Because while growth can lift people out of poverty, it cannot ensure escape from vulnerability to crises. Rich countries invest significantly in protecting their citizens from risks posed by hospitalization, disasters or old age.

Moving forward, social protection in India is poised for a fundamental transformation from a set of fragmented schemes to an integrated system - a fundamental point missed in the simplistic discussion about Universal Basic
Income (UBI) or quasi-UBI measures such as guaranteed income support. Successive state and central governments in India have invested in important building blocks of a social protection system. Budgets have been enhanced, a larger number of people are being covered, and a series of new programs have been launched with a focus on rights-based entitlements and technological innovations. The Socio-Economic Census (SEC) in 2011 - which collected new census data on asset and socio-demographic information can make the beneficiary identification process more transparent. Moreover, government-toperson payments have received strong impetus through campaigns to open bank accounts and the transition to digital payments through the Direct Benefit Transfer (DBT) initiative. The NITI Aayog and the Fourteenth Finance Commission have also enabled a framework for consolidation of schemes and for states to gain greater fiscal autonomy. New insurance schemes for health, life, crop-failure and accidents have been announced and given priority. India has signed on to achieve the UN SDG calling for "nationally appropriate social protection floors and systems." But progress towards outcomes remains ad-hoc, often restricted to specific schemes and states. And, the jump towards UBI or guaranteed income may fall into a similar trap. Instead, the focus needs to be on transitioning the many innovations that currently operate in silos into a harmonized 
Figure 1: Rich and Middle-Income Countries Spend Significantly on Social Protection

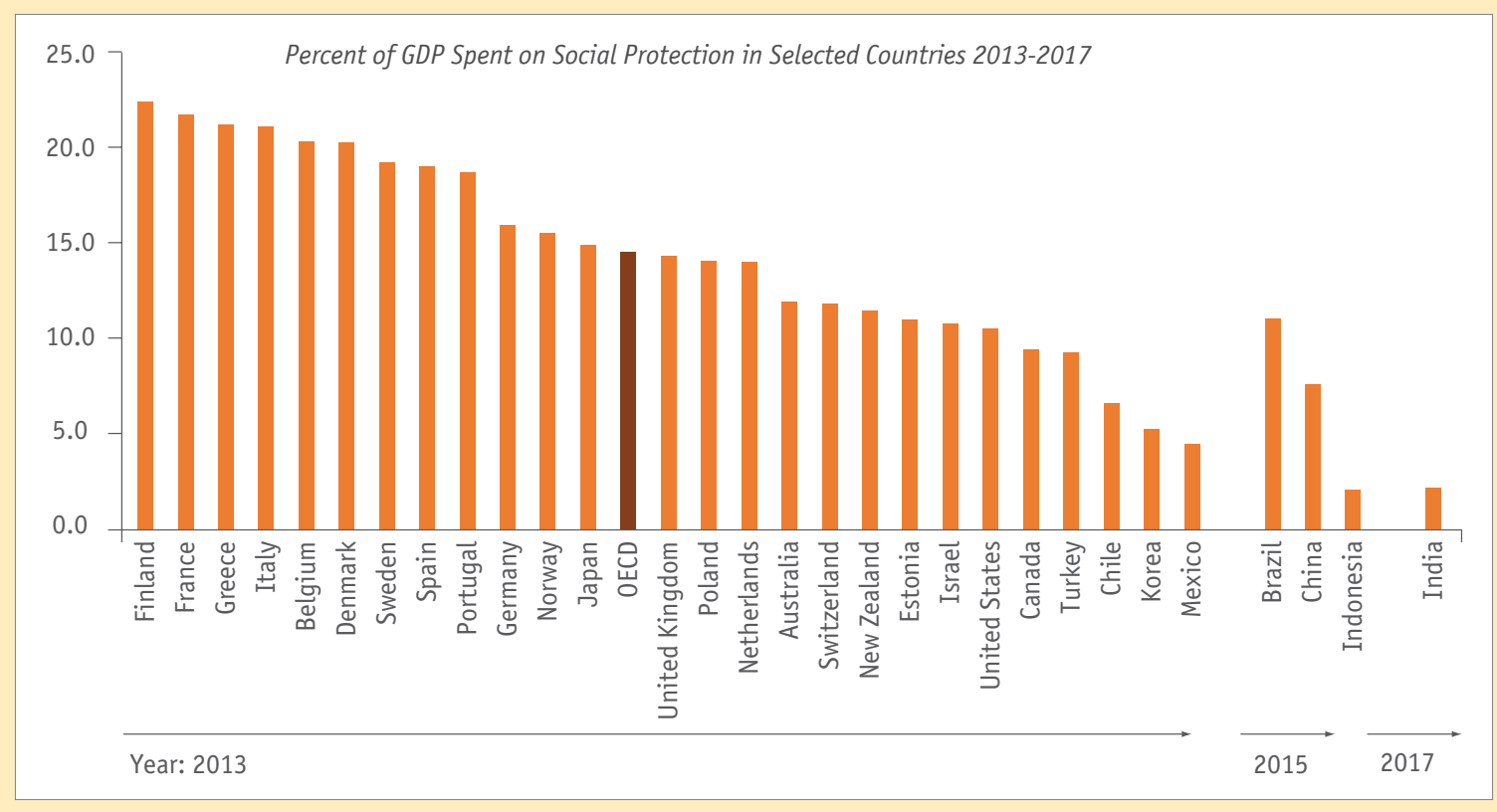

Source: OECD SOCX Database 2014, ADB SP Database 2016, World Bank Brazil Public Expenditure Review 2016 and India Union Budget 2018.

Note: The graph shows protection expenditure as a percentage of GDP for select countries for the latest year available. Definition of social protection expenditures are broadly consistent across sources of data. Spending on social protection in India, Brazil, China and Indonesia includes active labor market programs, social assistance for the poor and target groups through cash or kind transfers, social insurance (excluding military pensions) and elderly support. For OECD countries, social protection expenditures include active labor market programs, government contribution to pensions and elderly support, income support to the working-age population through incapacity benefits, family cash benefits, unemployment support and other public social services.

and scaled-up system of social protection. How should this be done?

At this stage of development, India needs an overarching social protection strategy to guide how various laws, innovations, schemes, staff and budgets will coordinate tactics to consolidate delivery costs, avoid administrative duplication and respond to India's diverse and changing risk profile.

A strategy assumes significance because a large share of social protection schemes operating in modern India are designed for the past. As they say, "The past is a foreign country, they do things differently there" and India, even of the recent past of 1977, was mired in chronic poverty, with a largely agrarian labor force, and barely networked. That India now only exists in pockets - the majority of the country has seen booming tele-digital and transport connectivity, sharp declines in income poverty and new neglected sources of risks related to climate, urbanization and migration. This is an important policy and cognitive shift that requires national and state governments to establish a nodal policy vehicle through which strategic thinking and coordination across schemes and states can be achieved.

As India moves towards defining a social protection strategy for its future, international experience suggest three important lessons.

Global experience highlights that universal and adequate insurance cannot be achieved by 
hundreds of state and central schemes operating in silos. Emerging economies have focussed on comprehensive coverage through program consolidation and convergence. Countries like Brazil have streamlined schemes and established integrated platforms which combine delivery of cash transfers to poor households with delivery of health, nutrition and education. China and Indonesia implement less than ten national social assistance programs respectively, far fewer than the hundreds of benefit transfer schemes managed by national and state governments in India.

International experience also emphasizes the need to move away from a one-size-fits-all model by allowing sub-national governments greater flexibility as political economy, labor markets, demographic attributes and risk profiles vary by location. The Chinese, Brazilian and Indonesian social protection architecture are heavily decentralized enabling local governments to design, plan and deliver a core basket of benefits within a nationally defined policy framework and budget.

Most importantly, global experience suggests that no strategy can create an effective social protection architecture without a capable state. Of late, there appears to be a growing political appetite to consider quasi-universal basic income (UBI) schemes at the national and state level. The 2019 budget has emphasized monthly farmer income support and Sikkim plans to implement full UBI. However, these programs require a strong tech-enabled delivery chain which can target and administer benefits. Ensuring technology is leveraged effectively without triggering exclusion and privacy violations requires robust regulation. As more flexibility is given to states, their capacity to plan, learn and implement programs must also be strengthened, particularly at the subdistrict level. Countries like Brazil and Mexico have invested heavily in local administration and social workers to manage dynamic social registries and public dealing. Designing solutions to local problems will require a frontline administration which has the time, talent, tools and authority to innovate and respond to citizen concerns. Lessons from the last-mile infrastructure created in other countries can help India design its own technology and rights enabled local state. The following series of articles identifies key challenges in building a capable social protection system in India.

India doesn't need to mimic programs in Brazil or China. It must incorporate international lessons as it evolves and catches up with the changing needs of its own people. It's time to think beyond singular schemes. A broader social protection strategy for a more urban, middle-income, mobile, diverse and decentralized India is urgently required.

An abridged version of this article was originally published in the Indian Express on February $19^{\text {th }}$, 2019. 


\section{POVERTY TO VULNERABILITY \\ Rebalancing Social Protection in India \\ Shrayana Bhattacharya, John Blomquist and Rinku Murgai}

A steady, safe, well-paid job is the best protection against economic hardship. But when this ideal situation is not possible, social protection programs help people become more resilient to the risks they face. of late, there is growing enthusiasm for basic income support as a core tool for social protection in India. But, income transfers cannot prepare or insure people against all shocks. Typically, a comprehensive social protection system requires three types of instruments to work together. First, promotional instruments invest in the ability of families to survive shocks on their own - by enhancing productivity, access to job opportunities and incomes through human capital infrastructure, wage legislation, labor policies, skills training and livelihood interventions. Second, preventive instruments aim to reduce the impacts of shocks before they occur by enabling households to use their savings from good times to tackle losses in tough times. This is mainly done through social insurance programs. Third, protective instruments mitigate the impacts of shocks after they have occurred through tax-financed redistribution from the non-poor to the poor. These programs would classically be called anti-poverty measures as they target social assistance or safety net programs to the poor or destitute, whether in kind or cash.

When social protection schemes were created in India after independence, most of the country was reeling from a period of famine, de-industrialization and multiple deprivations. Half the population was chronically poor, the country had an aggregate food deficit, financial and banking networks were under-developed, growth rates were weak and technology available for program administration was rudimentary. Therefore, India's policy makers focused almost exclusively on anti-poverty, protective instruments. But that India no longer exists, and the country's social protection system needs to evolve and catch up with the needs of its new demography and risk profile. Three stylized facts are important to guide this evolution.

First, despite the dramatic fall in households below the poverty line to 22 percent, the challenge of chronic poverty remains. India shelters pockets of deep poverty and these households are geographically clustered. A significant 15 percent of households that were poor in 2005 remained poor in 2012. Second, inequality across locations and demographic groups has increased.In 2012, the latest year for which estimates are available, the poverty rate of six of the poorest states in the country was twice that of other states. Seven low income states - Chhattisgarh, MP, UP, Odisha, Jharkhand, Rajasthan and Bihar - account for 45 percent of India's population but nearly 62 percent of its poor. Within states, poverty and vulnerability remain highest amongst Adivasis. Moreover, women are largely missing from the 
workforce and face risks to their mobility and well-being. Third, the majority of India is no longer poor. Instead, half of India is vulnerable. These are households that have recently escaped poverty with consumption levels that are precariously close to the poverty line and remain vulnerable to the risk of slipping back. Programs must ensure that those who've escaped poverty are able to sustain improvements.

As families move out of poverty and the middleclass grows, social protection programs can no longer be singularly focused on chronically poor households. For example, in 2016, a traditional safety net such as the Public Distribution System (PDS) expended sixteen billion dollars, the life and accident insurance programs spent less than sixteen million dollars together. Even in 2019, programs such as PDS and MGNREGS constitute a majority of social protection spending in India.

It's critical that programs help those vulnerable to poverty to anticipate and manage risks and shocks better, not only attempt to provide aid to relieve deprivations experienced by the poor. There are three types of portable tools needed by India's new vulnerable class to prevent them from falling back into poverty and debt traps-health insurance, social insurance (in case of death, accident and other calamities) and pensions. Portability is key to ensure migrants receive support while they try to build new lives in new places, as state governments often use residency criteria to target benefits.

Coverage of social insurance programs remains low in India, with only 4 percent of households using such programs. IHDS 2012 data shows that 27 percent of households report members using/benefitting from private insurance. Unsurprisingly, the bottom 20 percent report very low uptake of private options for marketbased insurance. Most Indian households - poor and non-poor - rely on personal savings to deal with health, accidents or climate shocks. Micro surveys and administrative data also highlight major gaps in pension and health insurance coverage.

Recent policies have taken steps in the right direction. The boost in crop insurance, new pension plans for the elderly, the rise in contributory pension schemes for those who have the wherewithal to save, and larger coverage of health insurance programs will help India re-balance its social protection architecture to match the needs of the rising numbers of its vulnerable people.

Given the huge diversity in the economic profile of India's states, a variety of approaches will be called for. For instance, the needs of the rising middle-class with access to private insurance markets in Delhi and Maharashtra will differ markedly from the needs of poorer states such as Uttar Pradesh and Bihar. Delhi should be enabled to spend its centrally allocated social protection resources differently from Uttar Pradesh. In states where many poor and vulnerable households are still not able to save enough to insure themselves against crises or times of high prices, social assistance will remain a core intervention. In low income states, traditional anti-poverty programs such as PDS or MGNREGS, if implemented well, can serve twin goals of protection and prevention by ensuring India's vulnerable don't become poor and that the poor live with dignity during times of drought or food price inflation. Effective safety nets can dramatically reduce the number of poor and the likelihood that poverty will be transmitted from one generation to the next. Strengthening their delivery systems is key, while allowing state governments to choose the optimal mix of preventive and protective programs to suit their state's needs within an umbrella social protection budget.

If insurance coverage is adequate and expands, many families would not need to rely on safety net transfers in the face of old age or health 
crises which would otherwise push households into long term poverty and debt traps. Thus, an increased emphasis on interventions that help anticipate risks should be expected, particularly in medium - and high-growth states.

In 2019, India is no longer a largely chronically poor country but a more unequal and vulnerable country with pockets of deep poverty. India's future shared prosperity will depend to a large extent on how its social protection system evolves and catches up with its diversity and demography.

An abridged version of this article was originally published in the Indian Express on March $4^{\text {th }}$, 2019.

6 PATHWAYS tO REDUCING POVERTY AND SHARING PROSPERITY IN INDIA | SCHEMES TO SYSTEMS: LESSONS FROM SOCIAL PROTECTION IN INDIA 


\section{THE FUTURE OF SOCIAL PROTECTION}

\section{India and the World}

\section{Michal Rutkowski}

Your daily office commute is delayed due to strikes against ride-sharing companies. Your nephew just joined his second start-up. Your daughter lands a job as a freelance journalist. Your street vendor who sells flowers down the street has been absent due to an illness. Your maid asks you to help contribute to a web-based pension product, she has a tough time applying for government social pension programs as she cannot prove that she has been living in Delhi for three continuous years.

India has made tremendous strides in poverty reduction in the first decade of the 21st century. However, economic growth has failed to generate enough stable and good jobs for its burgeoning working-age population. Employment has grown rapidly in construction and retail, gains in manufacturing jobs have been slow. And even within manufacturing, and in the organized sector more broadly, employment contracts have been shifting towards greater informality, as production is outsourced and new hires are taken on as contract workers without job security or social security. In 2012, over 90 percent of Indian workers were informal. As per the most recently available data, the share of contract labor in organized manufacturing reached 34 percent in 2011, up from 14 percent in 1996.
The changing nature of work is upending traditional employment globally. But as the gig economy, part-time jobs, contracts and other diverse and fluid forms of employment grow, what happens to the protections the traditional job market offered to people and workers? Most social protection systems in rich countries were developed at a time of "jobs for life," with social insurance based on mandatory contributions and payroll taxes on formal wage employment. But around the globe, this traditional, payroll-based insurance system is increasingly challenged by working arrangements outside standard employment contracts. In the U.S., pension plans are becoming a thing of the past. In India, Indonesia, Pakistan, Bangladesh and Nigeria - which combined account for about a third of the world's population - coverage of social insurance is single digit or almost so, with virtually no change detected over the past decades (Figure 1).

New ways of protecting people are needed. We need a new social contract and greater investment in people. As we examine the changing nature of work in our 2019 World Development Report, we are taking a look at how we can better protect people and workers in the new economy. There are three salient findings which must guide the future of social protection in India and the globe. 
Figure 2: Social insurance coverage in developing countries is generally low

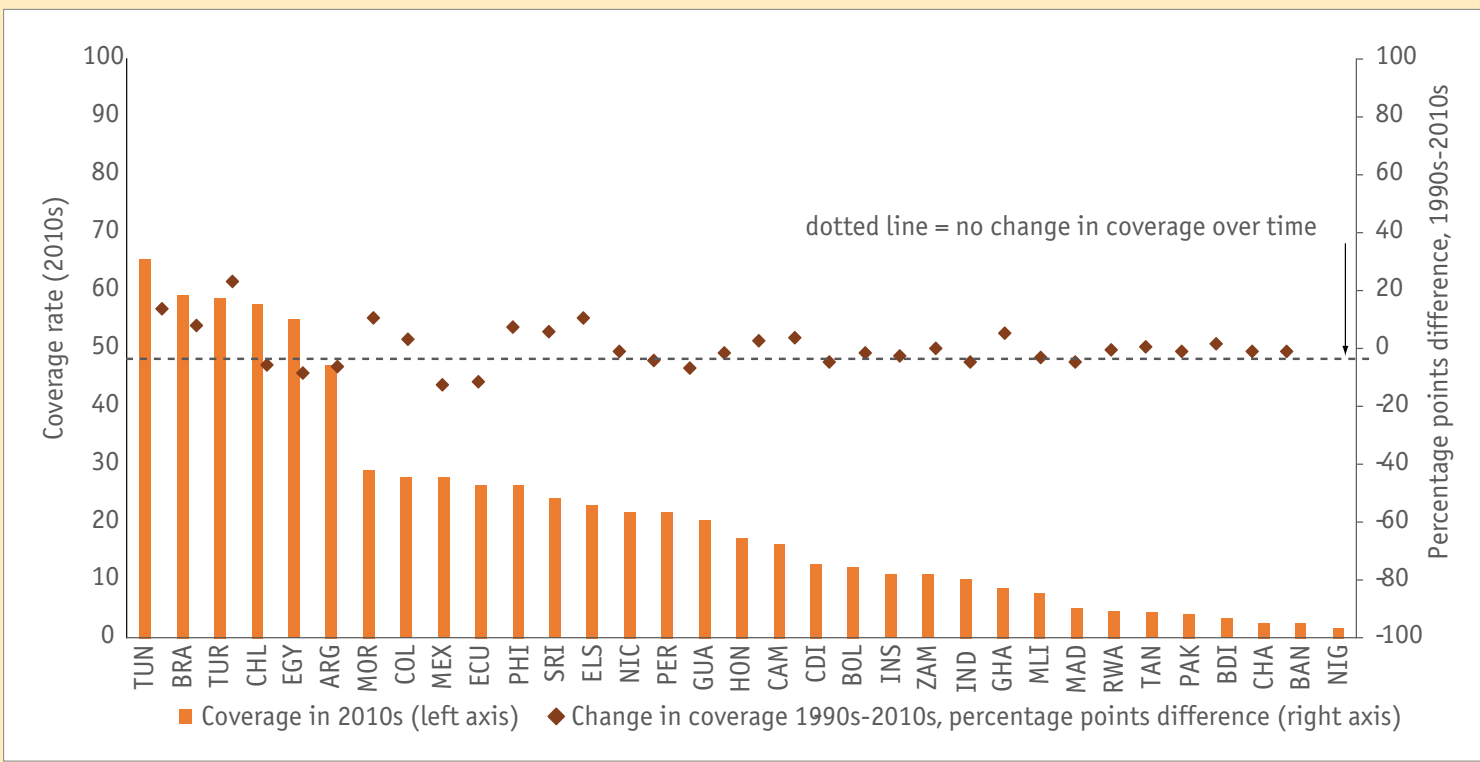

Source: World Bank pension database.

First, informality, which currently engulfs around 80 percent of labor markets in developing countries, is a premier bottleneck. Most workers - especially the poor - are engaged in informal sector activities with no or little access to social protection. Given the endemic nature of challenge and slow progress against it, most people would be better-off with a social protection system that does not depend on their work situation. India can teach the globe many lessons in creating such an architecture - as several new social insurance programs such as Atal Pension Yojana and the new health insurance scheme delink benefits from pay-roll contributions and reliance on a steady employer.

Second, social assistance programs which transfer benefits to protect the poorest from risk and ensure equity in societies, could be adapted and enhanced to include larger swaths of informal sector workers. In developed countries, there are a range of options starting with a means-tested Guaranteed Minimum Income (GMI) programs and ending with a Universal Basic Income. An intermediate option could be a Negative Income Tax that has relatively high threshold and gradual withdrawal of benefits, or a smaller GMI supplemented with other programs, such as universal child allowances and social pensions. However, as many discussions highlight, the feasibility of implementing such mechanisms at scale in India appear limited at present. This is not due to fiscal constraints alone, but state capacity concerns - neither of which are trivial. Prior to testing universal transfers, administrative building blocks for cash delivery and targeting need to be in place which minimize chances of exclusion, in addition to a clear social protection strategy on how different pre-existing schemes can be consolidated. The solution to a fragmented four-hundred scheme system cannot be creating a new income transfer scheme without consolidation of other programs.

Third, the notion of 'progressive universalism' can help guide such a strategy in ways that 
benefit the poor and vulnerable first. India must define a core basket of social security benefits relying on a mix of its current programs. Once guaranteed solid, basic protections are in place, people could keep upgrading their security with various progressively-subsidized schemes - with contributory social insurance where conducive conditions exist, but also an array of voluntary options where the state and markets can offer them.

Financing more investment in social protection is a formidable challenge globally. But several options leveraging carbon pricing, tech-enabled tax system reform and energy subsidy reform exist. For example, Vietnam could increase tax revenues by 11 percent by moving to a uniform VAT rate of ten percent. Excise taxes, for example on tobacco, are another source of potential revenue. It is estimated that nationally-efficient carbon pricing policies could raise substantial amounts of revenue-above six percent of GDP in China, Russia, Iran, and Saudi Arabia. These taxes could be paired with the elimination of energy subsidies, which amount to $\$ 333$ billion globally. Other forms of recurrent taxation may include immovable property taxes as well as a fair corporate tax system, which is currently plagued by loopholes in the international tax architecture. Just as technology improves delivery systems for social protection programs, it can also facilitate tax collection by increasing the number of registered tax payers and social security contributions. Reforms such as the Goods and Services tax can go a long way in bolstering state revenues to finance schemes and systems for the vulnerable.

The following chapter will suggest pathways of reform to some of India's largest social protection interventions, including pension programs, health insurance, the Public Distribution System and the Mahatma Gandhi National Rural Employment Guarantee Scheme. The latter two are among the largest anti-poverty measures in India and indeed the world, while the former are relatively new instruments for unorganized workers. However, all of them are relevant for India's future welfare architecture as they attempt to de-link social security benefits from a person's place of work.

An abridged version of this article was originally published in the Hindustan Times on February $18^{\text {th }}$, 2019. 


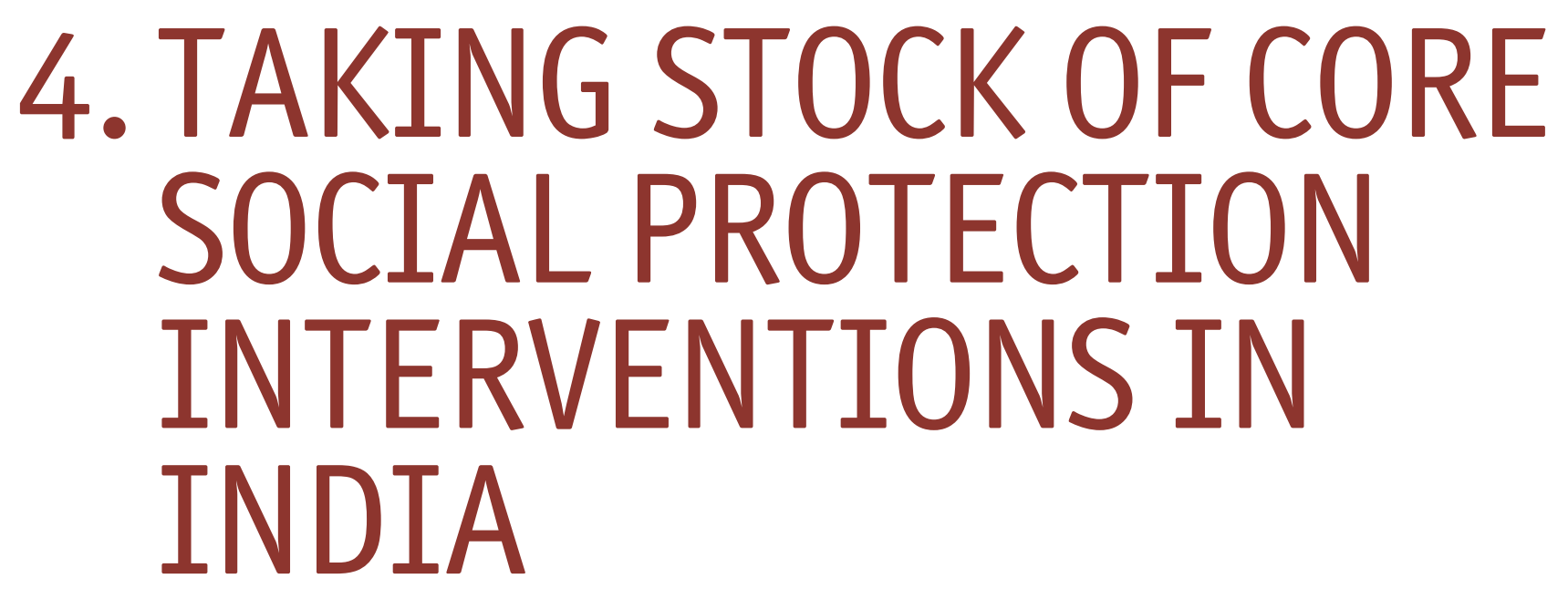

\subsection{Mind the Gap: Ageing and Pensions}

\section{Gautam Bhardwaj, Varsha Marathe and Robert Palacios}

While India is often characterized as a young country, by 2050, every fifth Indian will be above the age of sixty. An ageing population, with fewer children to depend on and changing family structures are creating one of the most important policy challenges for India. The question is: will India be able to ensure sustainable financial protection and dignity for its 104 million elderlywhose numbers are growing every year - by the time this demographic transition is complete?

The task will not be easy. Retirement support through pensions is crucial to any package of elderly support. At present, the gap between those who have pensions and those who don't is huge. Only 12 percent of Indians are covered by a formal pension scheme. As a result, the vast majority of the nearly 5 million Indians who join the ranks of the elderly every year face the grim prospect of poverty in their old age. The problem is further compounded by rising life expectancy nearly two decades at age 60 today, and the tiny savings of excluded individuals. Evidence from various sources suggests that those between
50 and 60 years of age do not have adequate pensions or retirement savings to support themselves for more than two years after they leave the workforce. Most of India's elderly rely on a combination of physical assets and informal family-based arrangements for support.

There are two tools to support the elderly when earnings cease. First, contributory pension programs - such as the National Pension Scheme (NPS) and the Atal Pension Yojana (APY) recently announced by the central government - can cover a considerable number of those who have the financial capacity to save for their retirement. However, such programs only suit a small number of people, either formal employees or those who have the wherewithal to save. In contexts where savings are low and incomes irregular, the second tool - tax-funded unconditional cash transfers, also known as social pensions become important to secure the future for those who are already old or who do not have the capacity to save for their old age. Evidence from countries such as China shows how rural social 
pensions tend to free up some of the support provided by children while also increasing health care consumption of the elderly.

In India, social pensions have emerged as a key tool to protect the elderly poor - serving nearly 23 million people. This is in keeping with global trends where old-age tax financed social pensions have proliferated over the last two decades. At the same time, contributory schemes have made important progress. The number of subscribers for NPS Lite and APY - targeted to weaker economic segments and unorganized workers have increased to nearly 15.7 million as of July 2018. But despite this expansion, coverage remains low - at barely 4 percent of India's 391.4 million unorganized workforce. Survey data across Delhi and Odisha suggest irregular incomes and behavioral rigidities in accessing financial and savings products can explain low uptake. If this continues, most of India's young informal sector workers, including those who have the capacity to save for their retirement, will have limited support during old age and fall back on tax-funded social protection programs when they are old.

To prevent this from happening, state and central governments will need a two-pronged approach. First, the currently young workforce must be encouraged to save for their old age by enrolling in long term retirement savings products such as APY. This could be done by encouraging individuals with PMJDY bank accounts to join contributory pension programs through new fin-tech tools. Such mass mobilization can allow India to generate strong volume of long- term retirement savings for the country. Such encouragement will need concerted efforts to make enrollment processes easier, testing autoenrollment options, sandbox pilots and boosting consumer confidence in financial products. Testing methods of auto-enrolment for the nearly 400 million Aadhar-seeded Jan Dhan Bank accounts can yield rapid results. The growth of digital transactions in India-where savings and monies can be transferred in a transparent and flexible manner - shall enable a new model of citizen-friendly and sustainable mode of pension financing which does not rely on payroll-taxes.

Second, for those who are already old or do not have the financial capacity to save for their twilight years by contributing to NPS and APY, tax-funded old age pensions must be enhanced. While many states have opted for near-universal eligibility criteria for social pensions, surveys highlight challenges in translating policy into practice due to cumbersome enrollment processes. Adequacy levels of India's pension benefits are lower than most middle-income countries. On a scale of 100 , the Mercer Global Pensions Index on scores the adequacy of India's pension benefit levels at 38.7, while China and Brazil receive a score of 53.4 and 72.5 respectively. Scaling up pension benefits and coverage needs to be pursued at missionmode pace. The lives and dignity of an entire generation of India's elderly is at stake.

An abridged version of this article was originally published in the Hindustan Times on February $20^{\text {th }}$, 2019. 


\subsection{Insuring India: Towards financial protection against health shocks}

\section{Sheena Chhabra and 0wen Smith}

The expansion of insurance coverage through the Ayushman Bharat - Pradhan Mantri Jan Arogya Yojana (PMJAY) has the potential to be a major milestone on the road to achieving universal health coverage and a minimum social protection floor in India. The need is real: out-of-pocket expenditures due to health crises are a leading cause of indebtedness in the country, and health shocks push over 4 percent of Indian households into poverty each year. These realities are inconsistent with the aspirations of a middleincome, middle-class society.

PMJAY, launched on September $23^{\text {rd }}$, aims to provide the poorest 40 percent of the population (about 100 million families) with health insurance covering over 1300 secondary and tertiary care packages at public and empanelled private hospitals, up to an annual limit of 5 lakh rupees. It builds on a decade of experience implementing government sponsored health insurance schemes in India. Rashtriya Swasthya Bima Yojana (RSBY) was launched in 2008 to provide health insurance coverage to Below Poverty Line (BPL) families. Over 20 states now have their own health insurance schemes. At their best, these schemes can expand access to private hospitals using public money, empower government hospitals to improve the quality of their services, and protect the poor and vulnerable from the costs of hospitalization. At their worst, the transactional nature of insurance and the complex web of stakeholders can overwhelm state oversight capacity, resulting in beneficiaries in name only, widespread fraud, and minimal impact on health and financial protection. India has experienced both.
There is a long list of issues related to health system development raised by PMJAY, but here we focus specifically on the potential (and limits) of PMJAY to enhance financial protection. We offer five observations.

First, while the intent to target the poorest 40 percent is laudable, it should be recognized that a far larger share of the population is in need of a safety net to protect against healthinduced financial shocks. India has moved from being mostly poor to mostly vulnerable. In fact, according to the National Sample Survey 2011 (the most recent available), the difference in monthly per capita expenditure by a household at the $40^{\text {th }}$ percentile of the population and another at the $80^{\text {th }}$ percentile is only about Rs 1,000 . This is dwarfed by the average cost of private hospitalization, which is about Rs 24,000 . For this reason, significantly higher coverage will ultimately be required to ensure financial protection for all. In fact a small number of states is aiming for universal coverage already.

Of course higher population coverage will mean a more costly program. This trade-off would have been easier to navigate if PMJAY had offered a more modest benefit package with fewer highend procedures. But expanding coverage will have the added advantage of making beneficiary identification much easier and reduce the risk of exclusion errors. Future options include extending eligibility to all ration cardholders, adopting exclusion instead of inclusion criteria (such as eligibility for all except formal sector workers), or going universal. These approaches 
would be simpler to administer than the current route of relying on the Socio-Economic Census (SEC) database for identification. Experience from other programs suggests that it is not easy to operationalize SEC, especially in denselypopulated urban environments.

Second, PMJAY cannot be expected to be the primary vehicle for reducing the health system's overall reliance on out-of-pocket payments. This is because total OOP is at least twenty times higher than the likely PMJAY budget, and it is mostly spent on drugs and outpatient care, which are not covered. At the current juncture, leaving these out of the benefit package makes sense on many levels. They do not impose the same one-time financial shock on a household as a hospitalization episode, even if they add up to more on an annual, population-wide basis. Empanelling outpatient providers and drug sellers would also be prohibitively complex, with huge scope for fraud and over-use. And since a large share of drug spending is selftreatment by a population that is substituting for inadequate medical care, any solution must focus on improving the quality of care on offer. This is easier said than done, but other reform initiatives under the umbrella of Ayushman Bharat - including the establishment of 150,000 health and wellness centers - could make an important contribution to this agenda.

Third, PMJAY beneficiaries must be empowered. This was a weak point of RSBY. Awareness campaigns to inform beneficiaries of their entitlements, including how and where to access services, will be essential to ensure they get the care they need on a cashless basis. Robust grievance redress mechanisms to help resolve patient complaints will also be important.
Fourth, while states are rightly in the driver's seat for PMJAY implementation, there are areas where the Center should take the lead. Among the most important is to ensure portability of coverage across state lines, a key feature of the scheme. This offers huge potential, especially to migrant populations and those residing in states with fewer hospitals offering high-quality care. But operationalizing this will require a centrallymanaged modality for beneficiary identification, pre-authorization, and claims management for cross-border patients.

Lastly, in the long-run, India's governments (the Center but especially states) will have to spend far more on health than they have in the past if financial protection against health shocks is to be assured. Globally there is a clear relationship - the more countries spend on health via the public purse, the lower the reliance on impoverishing and inequitable out-of-pocket spending by households. India's 00P share of 62 percent of total health expenditures is among the top ten in the world. The main reason is not insufficient revenues, but rather because less than 5 percent of government spending is allocated to health, much less than the lower middle-income country average. Reversing this pattern cannot be done overnight, but the first step is to start building a health system - not just a scheme - that is able to spend additional resources effectively. Achieving this would go a long way towards truly establishing health insurance programs as a core pillar of India's social safety net.

An abridged version of this article was originally published in the Hindustan Timeson February $21^{\text {st }}$, 2019. 


\subsection{The Unfinished Agenda of Mahatma Gandhi Rural Employment Guarantee Scheme}

\section{Shrayana Bhattacharya, Clement Imbert and Rinku Murgai}

With its audacity to legally guarantee each rural household 100 days of work per year through village Panchayats, India's Mahatma Gandhi National Rural Employment Guarantee Scheme (MGNREGS) has remained one of the world's most complex and ambitious programs to implement. At the time of its launch, MGNREGS changed the very face of social protection in India. The program's implementation architecture was an important innovation globally as well - with its focus on leveraging rights, technology tools, community-based accountability mechanisms and village Panchayats to respond to citizen demand for employment at scale.

What can the experience with MGNREGS tell us about the capability of the Indian state to implement large scale demand-driven programs? Three lessons are important.

First, despite the program's ups and downs, its implementation continues to function at globally unparalleled levels. More than a decade into its existence, the reach of MGNREGS remains impressive with nearly 51 million beneficiary households in 2017 generating 2342 million person-days of employment, and expenditures at 0.3 percent of GDP. Analysis of administrative data since MGNREGS's inception shows that program participation has picked up after a phase of contraction in 2013 and 2014.

Second, local administrators and civil society have been able to leverage the program's rightsbased design to ensure pro-poor targeting. MGNREGS was one of the first national programs to delink program participation from any poverty criteria as it did not use the Below Poverty Line method of targeting. This 'self targeting' design of MGNREGS appears effective in ensuring coverage of vulnerable populations and the poor. Most studies show that participation in the scheme favours poor households, and helps alleviate poverty and distress during crises. At relatively high consumption levels for all households, participation drops off sharply. The program also implemented quotas for women to prioritize female participation. In 2017, 53.5 percent of those provided employment through the program were women while 39.1 percent belonged to Scheduled Castes (SC) and Scheduled Tribes (ST).

Third, despite recent improvements, many states struggle to pay beneficiaries on time. In October 2017, the Supreme Court of India expressed concerns on the delays in MGNREGS wage payments. Most states have struggled in identifying an effective and speedy payment transfer mechanism for MGNREGS wage payments to beneficiaries. Major complaints revealed through household surveys and social audits data include non-issuance of dated receipts, non-payment of unemployment allowance, incomplete payment of wages, and especially, delayed payments.

At the same time, the program demonstrates the growing ability of the state to use information technology to tackle fund flow problems, with encouraging results. State and central governments have recognized the challenge of delivering timely wage payments and made 
concerted attempts to improve the speed and transparency of the benefit transfer process. State funds were established in 2011 to minimize the delays caused by the gap between state government requests for funds and central releases. In 2006, a majority of the muster rolls used to calculate wages were maintained in hard copy. By 2011, muster rolls were digitized for public review and 90 percent of program expenditure information was accessible on the MGNREGS MIS portals. Studies in Bihar and Andhra Pradesh highlight how re-engineering fund-flows through use of technology can reduce corruption and improve wage payment processes. Recent use of biometrically authenticated payments for wages also highlight the challenges imposed by technology, as activists and academics find exclusion and delays due to authentication failures. Ironing out technical glitches and improving infrastructure of payment systems is essential to ensure that intended benefits of the program are not undermined.
Theory and evidence suggest that public works can yield stronger welfare impacts than basic income transfers provided citizen demand for works is honored with supply of employment, and assets so generated are of high value. But, neither of these requirements can be achieved without a strong and capable Panchayat machinery. While the policy framework for ensuring flexibility in creating durable and locally valuable assets is in place, credible implementation requires investing in the ability of Gram Panchayats to define and plan their local shelf of works.

In fact, the inability of Panchayats to honor and respond to citizen demands stymies the program's poverty impacts. MGNREGS performance has been weak in poorer states, where it is needed the most. High levels of unmet demand for work under the scheme constrain poverty impacts. According to recent administrative data for 2017, the nine poorest states - with

Figure 3: The poor in poorer states struggle to use MGNREGS in full spirit

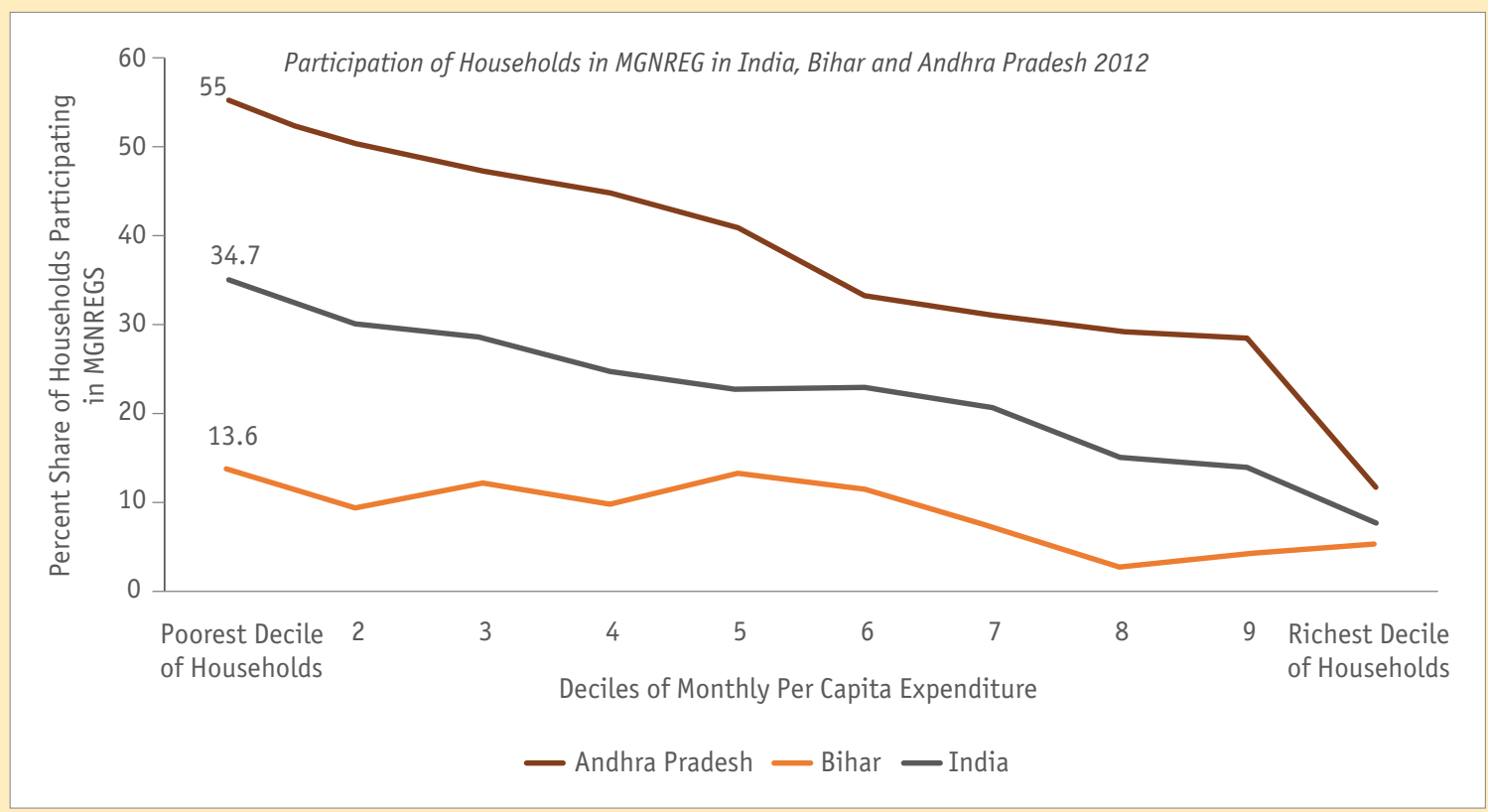

Source: NSS Employment surveys 2009-10 and 2011-12. 
poverty rates higher than the national poverty rate - account for only 32 percent of the total employment generated. Recent evaluations in Bihar and Rajasthan show that weak local implementation dampens the program's poverty effects despite effective targeting. As Figure 1 shows, a household in the poorest decile is four times less likely to participate in MGNREGS in Bihar than in Andhra Pradesh (13 percent against 55 percent). Strikingly, participation in MGNREGS in the poorest decile in Bihar is about the same as program participation in the richest decile in Andhra Pradesh (12 percent).

MGNREGS was one of the first programs to allocate large scale management powers and finances to Panchayats for locally responsive administration, mandating that 'Panchayats at the district, intermediate and village levels will be the principal authorities for planning and implementation' and minimum of 50 percent of the funds be executed by the Gram Panchayat. The result has been mixed. Evidence suggests that the responsibility of MGNREGS implementation raised stakes in local village level elections, increased accountability and motivated new candidates to run for office. On the flip side, there is abundant evidence from states such as Andhra Pradesh and West Bengal that MGNREGS gave new resources to local clientelistic networks.

To many, the challenge of reforming India's welfare administration seemed insurmountable with its paternalism, politics and corruption. Through making work a justiciable act, MGNREGS was successful in conceptualizing and forging a new compact between the administration, local political leadership and citizens. The scheme incentivized much needed policy and administrative focus on empowering Panchayats and reforming the front-line welfare bureaucracy. This part of the program's ambitious agenda remains critical and unfinished.

An abridged version of this article was originally published in the Hindustan Times on February $22^{\text {nd }}$, 2019. 


\subsection{The Public Distribution System: Anatomy of India's Food Subsidy Reforms}

\section{Harold Alderman, Shrayana Bhattacharya, Ugo Gentilini, Raghav Puri}

Protecting the poor from a rise in food prices remains a global policy priority. Indian households spend 45 percent of their income on food and many poor households rely on government subsidized grains for core cereal intake. Thus, programs to mitigate losses from food price shocks are an important part of India's social protection system.

India's food subsidy program continues to be one of the largest in the world. The Public Distribution System (PDS) provides nearly 800 million people with subsidized grain through a network of over half a million fair price shops. In 2017, the government spent some $\$ 16$ billion dollars on the program, or almost 1 percent of GDP. Viewed from the perspective of public administration and state capability, what can the history of the PDS teach us about social protection and subsidy reform in India?

First, the PDS tells us that large scale reform of leaky programs, even in poor states is possible. Thirteen years ago, the PDS data on coverage and leakage exposed alarming inefficiencies. In 2005 , only three out of ten of India's poorest households bought grains from fair price shops, while more than half the grains failed to reach intended beneficiaries. Policy makers were pessimistic about the program's future, reform seemed impossible, a Herculean challenge. Today, after concerted efforts from civil society, administrators, politicians and the judiciary, many states have seen improvements in the PDS. The program is reaching many more of India's poor, and the diversion of food-grains has reduced.

The numbers tell the story. In 2004-05, just 22.4 percent of Indian households reported buying food grains from fair price shops. This doubled to 44.5 percent in 2011-12, the highest since 1997, when the targeted PDS was introduced. Following the implementation of the National Food Security Act in 2016, coverage has further expanded. Administrative data for 2016, shows that 74 percent of Indian households possess a ration card; in 2012, nearly six out of ten poor households purchased grains from the PDS. All told, these improvements protected poor households from food price increases, and alleviated poverty during times of drought and high food inflation. While all-India decline in leakage has been moderate - going from 58 percent in 2004/05 to 43 percent in 2012-the reductions in leakages were particularly strong in the low income states of Bihar, Odisha, Jharkhand and Chhattisgarh. Micro-surveys in select low income states conducted in 2016 and 2017 found that citizens received nearly 90 percent of the subsidized grains to which they were entitled.

Second, the PDS experience teaches us that there are no magic-bullets to reform. Efforts required patience and calibration of various tools and the reform configuration varied across states. Political incentives helped, relaxed eligibility criteria expanded the number of people across stratas of society using the program. Improvements used 
Figure 4: Share (percent) of Households Purchasing Grains from PDS by State, 2004-2011

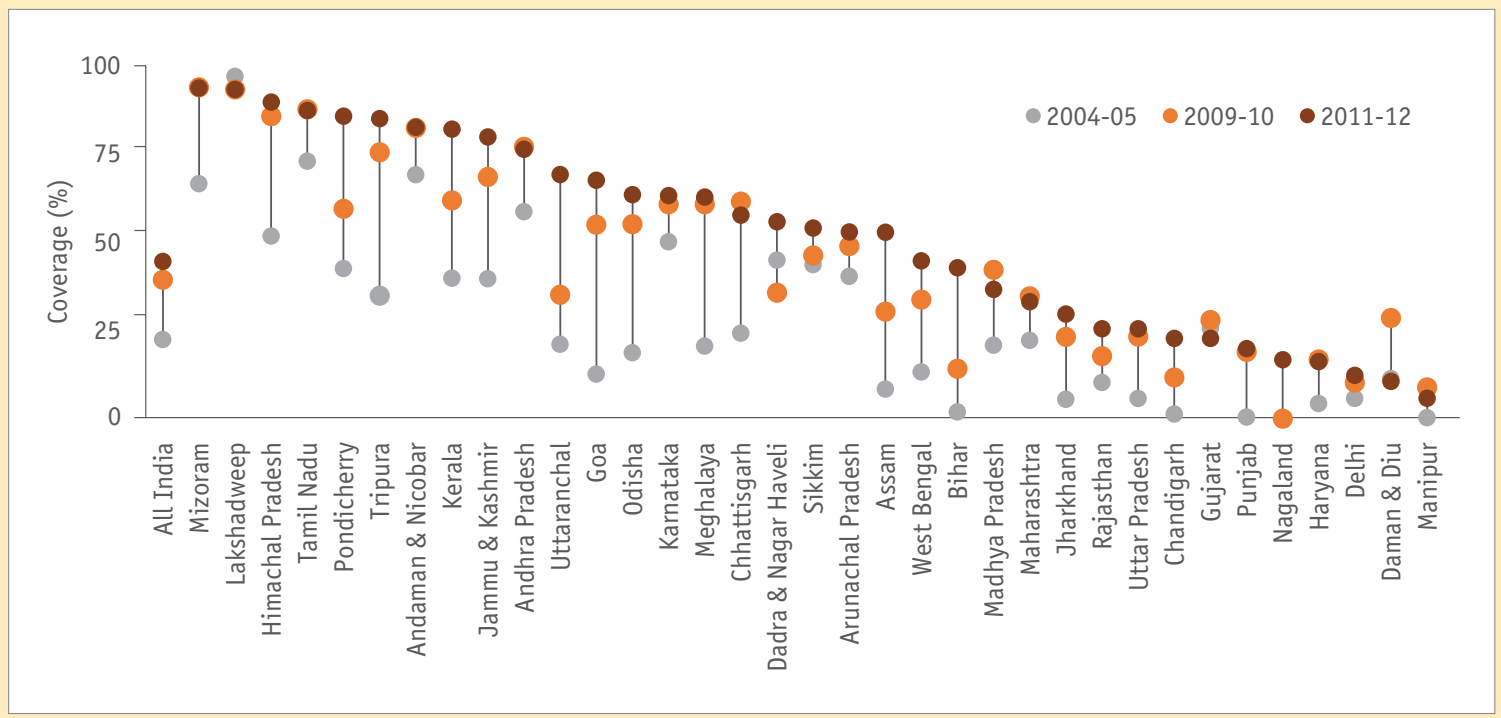

Source: NSSO: Authors Calculations using NSS Data.

technology to complement reforms including marrying a host of accountability tools to enable citizen-centricity.

Third, learning across state governments is key to scaling up reforms. State governments led the PDS reform process. Initially, Tamil Nadu, Kerala and Himachal Pradesh implemented reforms. These were later adapted by Andhra Pradesh, Chhattisgarh, Odisha and Bihar. Following this, the central government incorporated lessons learnt into national policies. Today, the central government has made modernization of the PDS supply chain a prerequisite for receiving subsidies under the National Food Security Act of 2013. Based on lessons from Tamil Nadu, the central government has also given states financial and technical support to digitize their ration card databases.

However, challenges remain. Critics highlight that the in-kind delivery of food subsidies is far too costly, and that the current subsidy regime encourages farmers to favor production of cereals which are procured by the central government for the PDS. Cash transfers are logically an alternative - although this begs the question of how the government would release procured grains under current policies into the market without simultaneous dismantling of the MSP and procurement system.

The NFSA empowers states to decide the modality of delivering food subsidies - in cash or kind. Urbanized Union Territories are already testing the use of cash in place of grains. While awaiting national procurement reforms, each state government can be assisted in making more informed decisions on how best to protect farmers and consumers from food price shocks based on diagnostics and feedback loops - as a gradual and sequenced path based on learning and local requirements.

A new set of proposals to reform the PDS center on "letting beneficiaries choose for themselves" - enabling people to express a preference for any given (digitally- 
enabled) transfer modality at the point of distribution - should that be cash, in-kind food or even vouchers. Where markets function well - cash assistance would ignite demand-based approaches that could help uphold consumer sovereignty, spark efficiency gains, and ignite competition among retailers.

However, a choice-based solution is yet to be implemented at scale in any developed country and may pose several nuts and bolts challenges. For one, a cash-or-kind system would place an even larger bet on technology: at any point in time, the system should be able to provide people what they want, anywhere. Whether the current system can accommodate the simultaneous, multiple and real-time demand of almost a billion people is an open question. Delivery of cash remains far more complex than is often imagined, even in urban areas. Recently, activists have also highlighted how the use of modern technology such as electronic-point of sale devices and biometrics may trigger delays and exclusion in food delivery - thereby eroding gains made in the recent past. Bolstering the capacity of local governments to test and use ICT effectively maybe more important than complex changes in the delivery chain.

More fundamentally, the choice approach may kick the can down the line and not fully address the underlying tension in the PDS - that is, its dual objectives of protecting families from price rise and stabilizing farmer incomes. Any reform on the social protection side should come in tandem with carefully crafted reforms on the agricultural and food price risk management sides. This is not a call for inaction, but for concerted crosssectoral policy. After all the PDS is not a program in vaccum, but part of a larger system-wide set of interventions.

An abridged version of this article was originally published in the Hindustan Times on February $20^{\text {th }}$, 2019. 


\section{TECHNOLOGY, STATE CAPABILITY AND SOCIAL PROTECTION}

\subsection{The Solutions State: Complementing Digital and Human Resources}

\section{Yamini Aiyar, Shrayana Bhattacharya and Lant Pritchett}

Across successive governments, India has emerged as a pioneer in building digital tools to improve program governance at the state and national level. Has all this technology helped? Robust evidence is mixed and limited.

Leveraging technology platforms for effective program delivery poses unique challenges. For citizens, the use of new tech-savvy tools can be alienating and intimidating. Using technology requires learning new ways to make demands and withdraw benefits, and new norms and modes of local behavior. Techo-optimists suggest that problems faced by local governments and citizens in using technology which manifest in reports of delays and exclusion due to poor infrastructure and connectivity are teething pains - side-effects of the transition to digital ways of interacting with government. Others fear that the side-effect could become the outcome, seeing the rapid deployment of new technologies as attacks on past improvements in delivery and giving rise to new forms of corruption. Should the state curb its enthusiasm for tech? Three design principles are key if technology is to truly and effectively help transform India's social protection systems.
First, technology must be seen as a tool, not a solution. We need to be clear-eyed about what problem we expect a particular technology to solve, and consistently assess the efficacy of the tools deployed. Solutions such as Aadhaar and DBT are often touted as gamechangers for Indian social protection. Are they? Depends what problem are they solving? If the problem is payment leakages emerging from "ghosts" or fake beneficiaries siphoning of monies, then as some early studies indicate, Aadhaar and DBT can make some difference. However, evaluated from the perspective of inclusion and citizen satisfaction, the evidence paints a different picture. In particular, the role of Aadhaar in delivering benefit transfers has come under significant academic, legal and civil society scrutiny for privacy concerns, delayed payments and triggering exclusion through authentication failures. Recent process assessments from Union Territories where governments are transferring food subsidies through electronic cash payments highlight the significant challenges posed by limited financial literacy and banking networks, even in urbanized environments. 
Importantly what Aadhaar enabled digital payments cannot do is ensure that benefits reach the most needy citizen. The 2019 budget announced the widely debated PM-KSN scheme for farmers. But, how will administrators identify and prioritize the small and marginalized farmers for whom the schemes is intended? Reviews of various programs highlight how exclusion continues to plague cash transfer programs such as social pensions in India. Identification of the poor who the social protection system seeks to prioritize has historically been problematic in India due to the poor design and execution of the BPL system. While biometrically authenticated Direct Benefit Transfers (DBTs) can verify if a certain person received a certain amount with maximum accuracy and minimum leakage, these tools cannot tell us if the person receiving the benefit is most in need of it. Aadhaar is proof of identity, not eligibility or priority. DBT can only provide a secure pipeline to transfer payments. Neither solves questions on who should be given greater priority for transfers. The problem of eligibility determination requires a very different set of interventions such as social registries. Without clearly identifying the problem, we can't analyze performance of technology tools - as these are simply enablers, parts of a larger solution.

Second, while technology is seen as a tool to enhance state capabilities, the effective use of technology requires a far more capable state. In social protection, a core motivation underpinning many tech-based reforms is the idea of removing human-interface from the delivery landscape by making processes as automated as possible. This idea is rooted in how Indian policy making often casts 'last-mile' cadres as apathetic - powerful corrupt entities who barely show up to work, are indifferent to the needs of citizens, dispense patronage and use power for personal gain. Yet the experience with various IT innovations suggests that the skill sets, capabilities and size of the local bureaucracy is critical to ensuring benefit transfer systems are inclusive, timely and citizen-friendly.

For example, within many poor states in India, the challenge of implementing electronic payments through DBT is exacerbated by weak last mile capacities, reliance on paper registers in view of poor presence of reliable banking outlets in the interior rural areas. The four crucial steps to undertake DBT - digitizing beneficiary databases, collecting the correct and functional financial address of a person, seeding the beneficiary database with identification information and ensuring mechanisms which deliver payments to beneficiaries without exclusion or delays - are fairly transaction intensive and non-trivial. Camps have to be organized, citizen information and consent for data sharing must be sought, program users need to be informed and counseled, bank accounts and identification proofs need to be produced; all these tasks require various agencies to coordinate at the local level. In various states, private players and state IT cadres have emerged to support routinized aspects of this work such as data entry, system development and digitization. However, tackling citizen claims and disputes on personal authentication, financial address information, payment settlements and other technology related pain-points rest with an understaffed, unmotivated and over tasked Panchayat and block office. Given the heterogeneity across India's villages and cities, identifying problems clearly requires a state that is able to deliberate with local stakeholders, while capturing and absorbing citizen feedback. Countries such as Brazil and Mexico have invested in large cadres of social workers for case management and citizen interface. So, technology changes the requirements for human resources, but does not make the need for strong local staff obsolete.

Third, policy makers need to be mindful of the new power asymmetries created by the use of technology. Programmers, government IT 
agencies and system developers are increasingly powerful in the new tech-savvy welfare state. These agencies hold vast amounts of private data on transactions and attributes. At the same time, the very language, nature and production of technology makes it opaque and distant from ordinary citizens, thus less tractable to local politics and activism. Many of us are often bewildered at the acronyms and terminology used in discussions on social programs. While you can perhaps find the truck driver who has diverted the PDS ration truck and agitate against local shop keepers or Panchayat officials, fighting against weak connectivity, a slow computer or a malfunctioning point-ofsale device is an alien concept for many Indians. If you thought your local Panchayat official was corrupt, you can complain to his superiors or politicians. But complaints triggered by misuse or errors in the use of tech-tools can be difficult to pick up, comprehend and process, even for the three of us, much more for citizens unfamiliar with technology. Thus, it's critical that government invest in methods to balance these asymmetries. Robust regulation and legal regimes, which are a focus of the debate in India following the Aadhaar judgement, are only a part of the solution. These laws must be complemented by systems that allow citizens to query and update their information through online and offline methods. For example, clearly codified data exchange, privacy and consent frameworks are necessary prerequisites to safeguard large scale collation of private data. This also requires building systems that can help channel and absorb feedback from citizens and local administrators into the design process for tech tools.

Reaping maximum gains from digital resources needs complementary and sophisticated investments in regulation, laws and human resources. After all, program governance involves deeply political and peopled landscapes; these can't be engineered in a social vacuum.

An abridged version of this article was originally published in the Indian Express on March $14^{\text {th }}$ 2019. 


\subsection{The Learning State: Processing Information for Social Protection}

\section{Abhijit Banerjee and Shrayana Bhattacharya}

Tough decisions lie ahead for India's social protection system. How can unorganized workers be empowered to access pensions or other income support programs? How do we make sure that benefits from the new PM-KSN are reaching the intended farmers? The ability of the state to process and consume information to answer such questions for program planning, monitoring and reform has always been critical and never more so than now. Program administrators need to be able to track program performance, learn quickly and incorporate lessons into new designs. In the past fifteen years, India has developed an enthusiasm to monitor schemes through hundreds of MIS portals. In fact, in the past two years, the national DBT Mission at the Cabinet Secretariat reports the development of 400 MISs for schemes to report payment progress on its national DBT portal. This is more than most middle-income-countries.

The vision is that these systems will enable citizens, government officials and politicians to gain access to all the information that they need to play their individual roles in a democratic society and enable the necessary exchange of knowledge for effective program implementation. Those managing food subsidies can monitor the movement of grains via geo-tagged trucks while the MGNREGS MIS informs administrators of payment delays and citizens use online grievance portals to register complaints.

Such information has the potential to be extremely valuable. One reason why these investments are happening now is that the cost of collecting and sharing information has gone down enormously over the last decades, thanks to the IT revolution. It is possible now for a mother at work to watch her toddler at play in a playschool by connecting her cell-phone wirelessly to a CCTV at the school through one of multiple available apps. And she might, for the first couple of days, but the novelty wears off fast. And then? The app will sit unused, unless there is a specific concern (say, the child is sick).

The problem is that information by itself is not insight; it has the potential for insight. Knowledge is not gathering mounds of information. It is processing that information and translating it into useable propositions-for example, "my child really looks tired, perhaps I should plan to leave early"-that makes people and organizations learners. The mother stops watching the CCTV feed because she needs to focus her mind on other tasks-she already has a tough time fending off the thousand other distractions that life throws at all of us. Processing the volume of information that a CCTV can generate every minute can clog the mind so fast that she needs to take defensive action.

Thus, so it is for organizations. It is not enough to generate information-someone has to process and translate data into something useable, and the more information you generate the harder that necessarily becomes-the more to sort through and discard. And if you have no guidance on how to do that sorting, then more information may actually hurt. Consistent with 
this, process evaluations suggest that in the wake of the MIS expansion, the local bureaucracy at the district and state level is drowning in MIS data, with neither the capacity nor the inclination to process it.

With the growing complexity and sophistication of India's social protection systems and schemes, building the capability of the local state to learn and reflect on information is critical. To build a genuine learning state - a state where everyone, citizens, bureaucrats and politicians use the information they need to generate insight and hold each other accountable, we need three building blocks.

First, we need to curate the information that gets highlighted. That does not mean censorshipcitizens should be able to access any information that they could reasonably need-but some filters have to go into choosing what to give prominence and why, based on a clear theory of how the information would be used, by whom and why that would matter enough to deserve the priority. This might seem obvious, but both of us have been witness to the many extremely far-fetched theories of change that get used to justify MIS interventions; in particular, the vision of a citizen who gets up in the morning and quickly files a MGNREGS problem report, then tweets about the policeman she observed taking a bribe on her way to work, spends her afternoon responding to a call from a government callcenter about PDS delivery and grain quality, followed by an evening reviewing the accounts of the municipality before turning in (to dream of accountability we're certain), is far-fetched. Even the most committed citizens have many other life problems to deal with, and activism is at best a part-time activity.

Second, we need to have clear designation of how the information will be used to provide incentives to actors within the system-if the news is bad, responsibility for it has to be clear. The MLA report cards developed by Satark Nagarik Sangathan and published in various newspapers before state elections, are a good example of prioritization (a small set of numbers, prominently displayed) and clear designationit says, more or less explicitly, "you are about to vote for your MLA, here is what he did." Research shows that this intervention changes how the voters vote, rewarding the best performers according to the report card and hurting the worst. This example also makes clear that whenever we prioritize information there are hard choices to be made. The report cards, to be effective, left many things out and an MLA could potentially complain that this was unfair to her achievements. There is no perfect resolution here, but there is a clear trade-off between effectiveness and being comprehensive.

Third, it is important to test whether the information is doing its job, whether it is being used to provide the required intelligence and insight. Even if the information collected is salient, it may lead to no change in behavior or local action. For example, the government of Karnataka built an ambitious MIS to biometrically track real-time attendance of nurses at health centers. The pilot hoped to hold front line staff accountable by making their attendance transparent. However, the reform made limited long run impact as state officials, local level bureaucrats, and locally elected bodies were reluctant to use the better-quality attendance data for enforcement due to a fear of generating discord among the staff.

To summarize, learning is not a logistical task. We have all too many examples now showing us that an MIS is not magic. The mere existence of call-centers and information infrastructure does not mean much without effective use and design. Even with the best technology and information monitoring, local administrators may choose not to convert the data they produce and own into knowledge and a body of actionable evidence, 
unless they have the people, time and training to do so. Without such resources in the design and use of MIS for social programs, information will become relentless noise, nuisance rather than an opportunity.

An abridged version of this article was originally published in the Indian Express on March $18^{\text {th }}$, 2019. 


\section{AUTHORS BIOS}

Junaid Ahmad is the Country Director for the World Bank in India since September 2016. He was formerly the Chief of Staff to World Bank Group President Jim Yong Kim. Prior to joining the President's office in January 2016, he was the Senior Director for the Water Global Practice at the World Bank. Ahmad joined the World Bank in 1991 and worked on infrastructure development in Africa and Eastern Europe. He spent 10 years as the deputy resident representative and principal economist in Johannesburg. In 2004, he was a team member of the World Development Report (WDR): Making Services Work for Poor People. From 2004-2008, he was the Sector Manager for Social Development in South Asia Region and subsequently for Urban Water \& Sanitation before taking on the latter responsibility for the Africa Region in 2010. He was also the Director for Sustainable Development in the Middle East and North Africa Region, a position he held from 2012-2014. He holds a PhD in Applied Economics from Stanford University, an MPA from Harvard University, and a BA in Economics from Brown University.

Yamini Aiyar is the President and Chief Executive of CPR. Her research interests are in the field of social policy and development. In 2008, Yamini founded the Accountability Initiative at CPR. Under her leadership, the Accountability Initiative has produced significant research in the areas of governance, state capacity and social policy. Yamini Aiyar is a TED fellow and a founding member of the International Experts Panel of the Open Government Partnership. She has also been a member of the World Economic Forum's global council on good governance. Previously, she has worked with the World Bank's Water and
Sanitation Program and Rural Development unit in Delhi, where she focused on action research aimed at strengthening mechanisms for citizen engagement in local government. Aiyar is an Alumna of the London School of Economics, St. Edmund's college Cambridge University, and St Stephen's College, Delhi University.

Harold Alderman is a Senior Research Fellow at the International Food Policy Research Institute. He holds both a master's degree in nutrition (Cornell) and a Ph.D. in economics (Harvard), has naturally gravitated to research on the economics of nutrition and food policy. He spent 10 years at the IFPRI prior to joining the World Bank in 1991. He rejoined IFPRI in 2012. While at the World Bank, he divided his time between the Development Research Group and the Africa region where he advised on social protection policy. His current research has focused on the linkages between nutrition and early child development and the means by which nutrition and social protection programs contribute to long term economic growth.

Abhijit V. Banerjee is the Ford Foundation International Professor of Economics at the Massachusetts Institute of Technology. In 2003 he co-founded the Abdul Latif Jameel Poverty Action Lab (J-PAL and remains one of the directors of the lab. Professor Banerjee is the recipient of the 2019 Sveriges Riksbank Prize in Economic Sciences in Memory of Alfred Nobel, awarded jointly with Esther Duflo and Michael Kremer "for their experimental approach to alleviating global poverty." He is the author of a large number of articles and three books, including Good Economics for Hard Times published in November 
and Poor Economics which won the Goldman Sachs Business Book of the Year in 2011, both coauthored with Nobel Prize winner Esther Duflo. Banerjee served on the U.N. Secretary-General's High-level Panel of Eminent Persons on the Post2015 Development Agenda.

Gautam Bhardwaj is co-founder of pinBox Solutions, Singapore - the only global pensionTech and expert advisory firm committed exclusively to digital micro-pension inclusion in Asia, Africa and the LAC. pinBox has developed delivery platform to help establish a digital micro-pension marketplace in any country within a few weeks and at a near-zero capital cost. He has over two decades of experience working with governments, regulators, DFIs and mainstream finance firms on designing, building and implementing inclusive pension arrangements for non-salaried informal sector workers. He founded a micro-pensions social enterprise in 2006 in India that helped deliver mainstream pension solutions to nearly 2.5 million lowincome individuals across over 100 districts of 14 Indian States. He has led several pension sector technical assistance projects and studies funded by ADB, World Bank, FSD and UNCDF for Bangladesh, Nepal, Rwanda, Papua New Guinea, Uganda, India, Nigeria, Indonesia and Kenya. He has also served on several governmental and regulatory committees on postal, pension, tax and financial sector reform.

Shrayana Bhattacharya is a Senior Economist in the World Bank's Social Protection and Jobs Practice based in New Delhi. In her role, she leads a series of World Bank policy reform engagements to strengthen the capability of state governments to strengthen the design and delivery of social protection programs. She also leads the World Bank's India Lighthouse learning partnership with the national Direct Benefit Transfer Mission, GoI to accelerate cross-state operational learning on leveraging technology to deliver cash transfer programs and reform social protection programs. Prior to joining the World Bank, she has worked with ILO, SEWA and Centre for Policy Research on a range of issues in the areas of state capability, social protection and informality. She completed her post-graduation in public administration and economics from Harvard University.

Dr. John Blomquist is the Global Lead for Delivery Systems in the World Bank's Social Protection Unit. He has specialized in the design and evaluation of social assistance and poverty alleviation programs, with experience in Asia, the FSU, Africa and Latin America. Prior to his current role, he led the World Bank's Social Protection and Jobs team in India, and supported the Direct Benefit Transfers agenda at the state level in India. Dr. Blomquist holds a Ph.D. in economics from the University of Pennsylvania.

Ms. Sheena Chhabra is a Senior Health Specialist, Health, Nutrition and Population Global Practice, South Asia Region, The World Bank. Ms. Chhabra is a seasoned health professional with nearly 30 years of experience. At the World Bank she leads the Analytic and Advisory Services for the India Universal Health Coverage Program and co-leads the National AIDS Control Support Project and the Uttarakhand Health Systems Development Project. Prior to joining the World Bank, Ms. Chhabra was the Team Leader, Health Systems Development at USAID/India. She has a strong track record of impacting national and state health programs related to universal health coverage, reproductive, maternal and child health, infectious diseases (HIV/AIDS and tuberculosis), nutrition, and water and sanitation in India. Ms. Chhabra has a Master's degree in Community Resource Management and Extension from the Lady Irwin College, University of Delhi.

Ugo Gentilini is the Global Lead Social Safety Nets with the Social Protection and Jobs Global Practice at the World Bank. His interests 
encompass the analytics and practice of social protection, including with an emphasis on urbanization, disaster risk, fragile states and food security. He holds a PhD in development economics and has published extensively on those topics. Before joining the Bank in 2013, he spent 12 years with the UN World Food Programme working on a range of cash and food-based safety net issues.

Clement Imbert is an Assistant Professor of Economics at the University of Warwick. His research focuses on governance and labor markets, specifically on the implementation and labor market effects of social programs. He has studied the Mahatma Gandhi National Rural Employment Guarantee Scheme extensively. Clŭment has done a post-doctoral fellowship at the University of Oxford. He holds a Ph.D. from the Paris School of Economics.

Rinku Murgai is a Lead Economist in the Poverty and Equity Global Practice of the World Bank, based in the New Delhi office. She has a keen interest in, and has published widely in the areas of poverty, vulnerability and public policy, encompassing poverty and inequality measurement; functioning of factor markets; and social protection design, delivery and evaluation. In her work at the World Bank, Rinku has contributed to Poverty Assessments, Development Policy Reviews, Impact Evaluations, Lending Operations, and Country Partnership Strategies. Most recently, she co-authored a Systematic Country Diagnostic for India. She has worked closely with Government on issues related to poverty monitoring, strengthening of statistical systems, and design and M\&E of safety nets. Rinku holds a Bachelor's degree in Biology and Economics from Swarthmore College, and a $\mathrm{PhD}$ in agricultural and resource economics from the University of California at Berkeley.
Robert Palacios is Global Lead for the Pensions and Social Insurance Group in the Social Protection and Labor Practice of the World Bank. Between 1992-1994, he was a member of the research department team that produced the World Bank's influential volume on international pension systems, "Averting the Old Age Crisis: Policies to Protect the Old and Promote Growth". Since 1995, he has divided his time between operational work and research with work in more than two dozen countries. His publications include articles and books on old age poverty, health insurance and a wide range of pension policy issues. Since 2014, he has been part of the multi-sectoral working group responsible for the World Bank's Identification for Development initiative, developing and piloting assessment tools in several countries with a focus on Africa.

Varsha Marathe is a Senior Financial Sector Specialist at the World Bank. She has led the Bank's support to the Pension Fund Regulatory and Development Authority on strengthening the eco-system for pension programs in India. She works on financial inclusion and pensions. She holds a master's degree in business administration and previously worked with the securities market regulator in Mumbai.

Lant Pritchett is the RISE Research Director at the Blavatnik School of Government, University of Oxford. Previously, he was a Senior Fellow at the Center for Global Development and Professor of the Practice of International Development at the Kennedy School of Government at Harvard University. In 2017 he published two co-authored books through 0xford University Press: Building State Capability and Deals \& Development: The Political Dynamics of Growth Episodes. He also published two solely authored books with the Center for Global Development, Let Their People Come (2006) and The Rebirth of Education (2013), and over a hundred articles 
and papers (with more than 25 co-authors) on a wide range of topics, including state capability, labour mobility, economic growth, and education, among many others.

Raghav Puri is a fifth year PhD student at the Department of Public Administration and International Affairs. His research focuses on the impact and implementation of health and nutrition programs in developing countries. His dissertation examines the effectiveness of conditional cash transfer programs in improving maternal and child health in India. He works with Douglas Wolf. Prior to attending Maxwell, Raghav worked for the Social Protection and Labor Global Practice a the World Bank in India. At the World Bank, he assisted national and state governments in evaluating and improving implementation of social protection programs such as subsidized food distribution, public works, health insurance and social pensions.

Michal Rutkowski is the Global Director for Social Protection and Jobs - overseeing the World Bank's work in developing systems that protect the poorest and vulnerable from crises and shocks, and supporting private sector-led growth. Mr. Rutkowski joined the World Bank in 1990. He was a country economist for the Russian Federation between 1995-1996, and after taking a brief leave from the Bank, returned as Sector Manager for social protection between
1998-2004, where he led a team of professionals working on pensions, labor market and social assistance reforms in 28 countries of Central and Eastern Europe and former Soviet Union, as well as in Turkey. Prior to joining the World Bank, he helped design the Polish pension system while serving as the Director of the Office for Social Security Reform. He also taught at the Institute of Economic Policy at the Warsaw School of Economics. Mr. Rutkowski holds an M.Sc. and Ph.D from Warsaw School of Economics and finished his post-graduate studies at the London School of Economics. He also graduated from the Executive Development program at the Harvard Business School in 1999, and from the Leadership for Collective Intelligence program run by Dialogos in 2010.

Owen Smith is a Senior Economist specializing in health financing with the World Bank, based in New Delhi since 2016. Previously he was based in Sri Lanka. Since joining the World Bank in 2005, he has worked on health financing, health policy, and social protection issues in the Europe and Central Asia and South Asia regions. Prior to joining the World Bank, he spent three years as a health economist with a consulting firm, and three years as a country economist at the Canadian Ministry of Finance. He has degrees in economics and international development from Queen's University and Harvard's Kennedy School. 


\section{Statistical Appendix* on Public Distribution System Prior to National Food Security Act (2013)}

Table 1: Household-level offtake of PDS grains - All Households and rural/urban, 2004/05, 2009/10 and 2011/12 (percent HH)

\begin{tabular}{|c|c|c|c|c|c|c|c|c|c|}
\hline \multirow{2}{*}{ State } & \multicolumn{3}{|c|}{ All Households } & \multicolumn{3}{|c|}{ Rural Households } & \multicolumn{3}{|c|}{ Urban Households } \\
\hline & $2004 / 05$ & $2009 / 10$ & $2011 / 12$ & $2004 / 05$ & $2009 / 10$ & $2011 / 12$ & $2004 / 05$ & $2009 / 10$ & $2011 / 12$ \\
\hline $\begin{array}{l}\text { Andaman \& } \\
\text { Nicobar }\end{array}$ & 68.9 & 82.2 & 82.3 & 67.6 & 87.3 & 86.9 & 71.5 & 73.6 & 74.6 \\
\hline $\begin{array}{l}\text { Andhra } \\
\text { Pradesh }\end{array}$ & 58.5 & 76.8 & 76.1 & 66.4 & 87.3 & 89.3 & 35.5 & 50.2 & 49 \\
\hline $\begin{array}{l}\text { Arunachal } \\
\text { Pradesh }\end{array}$ & 40.2 & 48.8 & 52.8 & 39.6 & 46.7 & 52.2 & 45.3 & 57.2 & 55.6 \\
\hline Assam & 8.4 & 30.3 & 52.7 & 8.9 & 31.9 & 55.2 & 3.4 & 16.5 & 31.4 \\
\hline Bihar & 1.9 & 14.1 & 42.7 & 1.8 & 14.7 & 44.9 & 2.3 & 9.3 & 22.5 \\
\hline Chandigarh & 1.3 & 11.7 & 22.7 & 6.8 & 0 & 9.4 & 0.7 & 13.8 & 23.7 \\
\hline Chhattisgarh & 24.2 & 61.4 & 57.5 & 25.7 & 66.2 & 61.9 & 15.6 & 39.2 & 41.6 \\
\hline $\begin{array}{l}\text { Dadra \& } \\
\text { Nagar Haveli }\end{array}$ & 44.8 & 35.6 & 55.7 & 45.7 & 45.8 & 72.7 & 37.8 & 4.9 & 32 \\
\hline Daman \& Diu & 11.3 & 28.5 & 10.6 & 14.7 & 42 & 2 & 4.9 & 11.8 & 24.2 \\
\hline Delhi & 5.7 & 10.2 & 12.3 & 5.9 & 40 & 19.5 & 5.6 & 8.6 & 11.7 \\
\hline Goa & 12.6 & 54.8 & 67.4 & 14 & 59.6 & 74.1 & 10.2 & 42.6 & 61.1 \\
\hline Gujarat & 25.5 & 27.9 & 22.7 & 34.1 & 38.2 & 32.5 & 8.9 & 11.1 & 8.4 \\
\hline Haryana & 4.3 & 16.8 & 16.2 & 3.5 & 19.8 & 18.4 & 6.6 & 9.9 & 11 \\
\hline $\begin{array}{l}\text { Himachal } \\
\text { Pradesh }\end{array}$ & 51.6 & 85.5 & 89.5 & 54.9 & 88.4 & 93.9 & 20.2 & 55.4 & 53.2 \\
\hline $\begin{array}{l}\text { Jammu \& } \\
\text { Kashmir }\end{array}$ & 39.5 & 68.3 & 79.6 & 35.7 & 68.5 & 80.8 & 51 & 67.7 & 75.4 \\
\hline Jharkhand & 5.5 & 23.1 & 29.6 & 5.8 & 26.4 & 34.9 & 3.4 & 9.9 & 9.4 \\
\hline
\end{tabular}

* For dissemination purposes, data on PDS coverage and leakage are presented upto 2011-12, which is the last round of nationally representative data available on use of PDS from the National Sample Survey Office. Estimates do not necessarily represent current coverage or leakage rates in the PDS, as the National Food Security Act 2013 has expanded the programme significantly at the state level, with strong investments in reducing leakages through ICT. 


\begin{tabular}{|c|c|c|c|c|c|c|c|c|c|}
\hline \multirow{2}{*}{ State } & \multicolumn{3}{|c|}{ All Households } & \multicolumn{3}{|c|}{ Rural Households } & \multicolumn{3}{|c|}{ Urban Households } \\
\hline & $2004 / 05$ & $2009 / 10$ & $2011 / 12$ & $2004 / 05$ & $2009 / 10$ & $2011 / 12$ & $2004 / 05$ & $2009 / 10$ & $2011 / 12$ \\
\hline Karnataka & 50 & 60.6 & 63.1 & 60.3 & 76.2 & 76.1 & 26.8 & 31.3 & 40.4 \\
\hline Kerala & 39.7 & 61.7 & 81.8 & 41.6 & 64.2 & 85 & 33.6 & 54.4 & 72.9 \\
\hline Lakshadweep & 96.7 & 93 & 93 & 98.5 & 97.4 & 93.9 & 94.8 & 88.7 & 92.2 \\
\hline $\begin{array}{l}\text { Madhya } \\
\text { Pradesh }\end{array}$ & 20.8 & 42.1 & 36.6 & 23.5 & 47.3 & 40 & 11.8 & 26.2 & 26.5 \\
\hline Maharashtra & 22.1 & 34.6 & 33.1 & 30.8 & 49.4 & 48.1 & 9.2 & 13.8 & 15.2 \\
\hline Manipur & 0.3 & 8.9 & 5.8 & 0.4 & 8.2 & 6.5 & 0.2 & 10.7 & 3.9 \\
\hline Meghalaya & 20.5 & 60.6 & 62.6 & 23 & 66.6 & 69.6 & 3.8 & 31.5 & 36.5 \\
\hline Mizoram & 66.4 & 93.6 & 93.5 & 71.7 & 95.6 & 97.7 & 58.4 & 91.2 & 88.6 \\
\hline Nagaland & 0.2 & 0 & 16.7 & 0.2 & 0 & 20.7 & 0.2 & 0 & 9.2 \\
\hline Odisha & 18.6 & 55 & 63.3 & 20.6 & 59.1 & 68.2 & 6.5 & 30.1 & 35.8 \\
\hline Pondicherry & 42.4 & 59.3 & 85.5 & 71.3 & 81.1 & 83.1 & 26.5 & 47.7 & 86.8 \\
\hline Punjab & 0.5 & 18.9 & 19.8 & 0.3 & 22.3 & 25.2 & 0.8 & 12.6 & 10.4 \\
\hline Rajasthan & 10.2 & 17.7 & 25.4 & 12.5 & 18.1 & 27.7 & 2.1 & 16.3 & 18.1 \\
\hline Sikkim & 43.5 & 46.2 & 53.9 & 48.1 & 53.4 & 63.4 & 7.2 & 1 & 8.8 \\
\hline Tamil Nadu & 72.7 & 87.4 & 87.1 & 83.7 & 95.1 & 94.7 & 55.1 & 77.8 & 77.6 \\
\hline Tripura & 34.8 & 75.3 & 84.8 & 38.3 & 77.5 & 88.1 & 13.5 & 63.7 & 66.8 \\
\hline Uttar Pradesh & 5.7 & 23.2 & 25.4 & 6.3 & 23.7 & 27 & 3.1 & 21.2 & 19.7 \\
\hline Uttaranchal & 21 & 35 & 69 & 26.6 & 40.4 & 73.7 & 2.9 & 19 & 55 \\
\hline West Bengal & 13.2 & 33.7 & 44.6 & 15 & 38.8 & 51.2 & 7.6 & 18 & 26.5 \\
\hline All India & 22.4 & 39.3 & 44.5 & 24.8 & 43.3 & 50 & 15.4 & 28.2 & 30.7 \\
\hline
\end{tabular}


Table 2: Household-level offtake of PDS grain by quintile by state, 2004/05 and 2011/12 (percent)

\begin{tabular}{|c|c|c|c|c|c|c|c|c|c|c|}
\hline \multirow{2}{*}{ State } & \multicolumn{5}{|c|}{$2004 / 2005$} & \multicolumn{5}{|c|}{$2011 / 12$} \\
\hline & Q1 & Q2 & Q3 & Q4 & Q5 & Q1 & Q2 & Q3 & Q4 & Q5 \\
\hline Andaman \& Nicobar & 68.2 & 73.6 & 76.9 & 74.1 & 50.8 & 84.8 & 91.6 & 88 & 86.8 & 60.3 \\
\hline Andhra Pradesh & 76.5 & 74.1 & 64.8 & 53.1 & 23.9 & 94.5 & 89.6 & 86.4 & 71.7 & 38.1 \\
\hline Arunachal Pradesh & 37.6 & 41.4 & 47.8 & 34.1 & 40.3 & 54.6 & 50.7 & 52.9 & 52.4 & 53.6 \\
\hline Assam & 19.8 & 11.4 & 5.9 & 2.7 & 2.2 & 65.8 & 56.7 & 54.8 & 51.6 & 34.4 \\
\hline Bihar & 3.4 & 2.4 & 1.4 & 1 & 1.1 & 59.8 & 54.8 & 41.5 & 37.3 & 20.1 \\
\hline Chandigarh & 3.9 & 0.6 & 0 & 1.9 & 0 & 35.2 & 32.6 & 28.9 & 5 & 11.8 \\
\hline Chhattisgarh & 45.7 & 22.4 & 22.8 & 19.6 & 10.5 & 79.9 & 73.3 & 63 & 49.2 & 21.9 \\
\hline Dadra \& Nagar Haveli & 54.7 & 62.5 & 43.2 & 37.5 & 25.7 & 86.4 & 54.8 & 78.2 & 45.9 & 12.2 \\
\hline Daman \& Diu & 31.8 & 19.6 & 0 & 3.4 & 0 & 21.9 & 17.4 & 5.6 & 4.3 & 3.5 \\
\hline Delhi & 14.8 & 4.4 & 3 & 4.2 & 1.8 & 23.2 & 21.2 & 8.3 & 7.7 & 1.2 \\
\hline Goa & 33 & 21.5 & 4.2 & 0.4 & 3.4 & 90.2 & 71.7 & 69.9 & 55.4 & 49.7 \\
\hline Gujarat & 46.2 & 37.2 & 27.4 & 13.8 & 2.7 & 45.6 & 28.4 & 27.4 & 8.5 & 3.5 \\
\hline Haryana & 8.3 & 7.8 & 3.2 & 1.5 & 0.7 & 42.5 & 21.9 & 9.9 & 4.7 & 1.7 \\
\hline Himachal Pradesh & 69 & 59.9 & 51 & 48.1 & 29.9 & 98.3 & 95.5 & 94.4 & 88.9 & 70.4 \\
\hline Jammu \& Kashmir & 57.2 & 46.7 & 39.8 & 32.9 & 21 & 86.9 & 91.3 & 85.8 & 80.1 & 53.7 \\
\hline Jharkhand & 11.4 & 5.8 & 5.3 & 2.2 & 2.5 & 53.5 & 35.8 & 28.3 & 21.8 & 8.3 \\
\hline Karnataka & 74.7 & 60.9 & 54.9 & 44 & 15.6 & 83.3 & 72.9 & 73.5 & 58.9 & 26.8 \\
\hline Kerala & 66 & 44.4 & 42.1 & 26.5 & 19.3 & 96.1 & 92.5 & 83.7 & 75.4 & 61.4 \\
\hline Lakshadweep & 98.1 & 100 & 99.1 & 97.6 & 88.1 & 100 & 100 & 100 & 92.5 & 71.8 \\
\hline Madhya Pradesh & 35.4 & 28.7 & 22.1 & 12.8 & 4.8 & 63.8 & 42.1 & 37 & 28.1 & 11.8 \\
\hline Maharashtra & 40.5 & 31.1 & 21.3 & 13.2 & 4.5 & 65.6 & 45.3 & 29.5 & 18.4 & 6.4 \\
\hline Manipur & 0.7 & 0 & 0.4 & 0 & 0.4 & 2.8 & 5.3 & 9.1 & 8.7 & 3.1 \\
\hline Meghalaya & 33.3 & 31.5 & 19 & 13.5 & 4.9 & 82.7 & 79.2 & 71.6 & 47.9 & 31.5 \\
\hline Mizoram & 75.6 & 75.5 & 74 & 64.2 & 42.8 & 98.8 & 99.5 & 98 & 91.8 & 79.2 \\
\hline
\end{tabular}

32 PATHWAYS TO REDUCING POVERTY AND SHARING PROSPERITY IN INDIA | SCHEMES TO SYSTEMS: LESSONS FROM SOCIAL PROTECTION IN INDIA 


\begin{tabular}{|c|c|c|c|c|c|c|c|c|c|c|}
\hline \multirow{2}{*}{ State } & \multicolumn{5}{|c|}{$2004 / 2005$} & \multicolumn{5}{|c|}{$2011 / 12$} \\
\hline & Q1 & Q2 & Q3 & Q4 & Q5 & $\mathbf{Q 1}$ & Q2 & Q3 & Q4 & Q5 \\
\hline Nagaland & 0.2 & 0 & 0 & 0.7 & 0 & 20.3 & 24.9 & 18.6 & 14.5 & 5.3 \\
\hline Odisha & 41.4 & 25.7 & 15.2 & 7.6 & 3.2 & 82.3 & 72.1 & 67.6 & 58.4 & 36.1 \\
\hline Pondicherry & 73.7 & 49.9 & 41.9 & 24.2 & 21 & 98.1 & 82.5 & 94.6 & 78.1 & 74.2 \\
\hline Punjab & 0.3 & 0.9 & 0.8 & 0.2 & 0.2 & 41.2 & 26.4 & 18.8 & 9.5 & 3.3 \\
\hline Rajasthan & 20.8 & 11.1 & 10.4 & 5.2 & 3.5 & 47 & 26.2 & 24.4 & 22.5 & 7 \\
\hline Sikkim & 82.1 & 56.8 & 42.1 & 27.3 & 9.1 & 90.1 & 83.5 & 55.5 & 33.1 & 7 \\
\hline Tamil Nadu & 91.3 & 88.9 & 82.8 & 65.6 & 34.7 & 97.9 & 94.4 & 92.4 & 86.9 & 63.7 \\
\hline Tripura & 74.1 & 50.2 & 22.8 & 17.9 & 8.9 & 96.9 & 87.9 & 87.8 & 84.7 & 66.5 \\
\hline Uttar Pradesh & 11.7 & 7.2 & 3.9 & 3.8 & 1.7 & 45 & 28.8 & 24.2 & 18.7 & 10.4 \\
\hline Uttaranchal & 34 & 23.8 & 23.6 & 18.8 & 4.9 & 83.2 & 81.4 & 82.9 & 60.4 & 36.9 \\
\hline West Bengal & 23 & 16 & 13.3 & 9.3 & 4.6 & 60.6 & 51.6 & 48 & 39.3 & 23.3 \\
\hline All India & 31.6 & 27 & 23.2 & 19.5 & 10.8 & 60 & 49.7 & 46.4 & 39.9 & 26.6 \\
\hline
\end{tabular}

Source: Bank Staff Estimates using NSSO 61st and $68^{\text {th }}$ Rounds. 
Table 3: Leakage from Household PDS offtake as share of official offtake by state, 2004/05 and 2011/12 (percent)

\begin{tabular}{|c|c|c|c|c|c|c|c|c|}
\hline \multirow{2}{*}{ State } & \multicolumn{2}{|c|}{ World Bank } & \multicolumn{2}{|c|}{ Gulati and Saini } & \multicolumn{2}{|c|}{ Himanshu and Sen } & \multicolumn{2}{|c|}{ Dreze and Khera } \\
\hline & $2004 / 05$ & $2011 / 12^{*}$ & $2004 / 05$ & $2011 / 12$ & $2004 / 05$ & $2011 / 12$ & $2004 / 05$ & $2011 / 12$ \\
\hline Andhra Pradesh & 31.1 & 16.6 & 23.2 & 11.1 & 25.4 & 7.8 & 23.2 & 22 \\
\hline Arunachal Pradesh & 61 & 46.3 & & 17.6 & 46.5 & 25.2 & 0 & 0 \\
\hline Assam & 89.4 & 51.8 & 88.7 & 60.9 & 88.1 & 45.2 & 88.7 & 50.7 \\
\hline Bihar & 92.9 & 29.1 & 91 & 68.7 & 91.2 & 12.2 & 91 & 24.4 \\
\hline Chhattisgarh & 51.8 & 16.9 & 51.8 & & 49.5 & 0.3 & 51.7 & 9.3 \\
\hline Delhi & 91.2 & 85.6 & & 82.6 & 89.5 & 80.6 & & \\
\hline Gujarat & 56.7 & 72.9 & 51.7 & 72.2 & 50.4 & 69 & 51.7 & 67.6 \\
\hline Haryana & 84.2 & 52.9 & 82.7 & 70.3 & 83.5 & 51.1 & 82.7 & 49 \\
\hline Himachal Pradesh & 27.3 & 26.2 & 27 & 22.5 & 24.7 & 20.6 & 27 & 27.1 \\
\hline Jharkhand & 86.8 & 51.5 & 85.2 & 74.9 & 84.2 & 34.5 & 85.2 & 44.4 \\
\hline Karnataka & 36.1 & 34.7 & 28.7 & 46.4 & 27.7 & 27.4 & 28.7 & 34.7 \\
\hline Kerala & 29.4 & 29.5 & 25.6 & 43.2 & 27.4 & 23.6 & 25.6 & 37.1 \\
\hline Madhya Pradesh & 50.3 & 50.6 & 50.1 & 49.3 & 46.4 & 42.1 & 50.1 & 51.5 \\
\hline Maharashtra & 52.8 & 47.0 & 49.3 & 54.9 & 47.7 & 41.3 & 49.3 & 48.2 \\
\hline Manipur & 98.4 & 96.2 & & 97.8 & 97.9 & 95.4 & & \\
\hline Meghalaya & 71 & 56.4 & & 67 & 64.7 & 49.5 & & \\
\hline Mizoram & 59.4 & 8.0 & & 15.2 & 44.7 & -5.3 & & \\
\hline Nagaland & 100 & 93.4 & & 94.7 & & & & \\
\hline Odisha & 75.8 & 30.7 & 76.3 & 36.8 & 74.8 & 15.5 & 76.3 & 25 \\
\hline Punjab & 94.8 & 60.3 & 93.2 & 60.7 & 94.2 & 56.5 & 93.2 & 58.8 \\
\hline Rajasthan & 59.3 & 62.2 & 93.9 & 66.3 & 55.3 & 55.6 & 93.9 & 60.9 \\
\hline Sikkim & 48.9 & 55.1 & & & 43.5 & 44 & & \\
\hline Tamil Nadu & 12.6 & 14.8 & 7.3 & 12.2 & -2.4 & 6.7 & 7.3 & 11.9 \\
\hline
\end{tabular}

* The estimates for 2011/12 are calculated using the official FCI data for central allocations plus additional allocation made during the year. Using only central allocations gives results similar to Himanshu and Sen estimates for 2011/12. 


\begin{tabular}{|c|c|c|c|c|c|c|c|c|}
\hline \multirow{2}{*}{ State } & \multicolumn{2}{|c|}{ World Bank } & \multicolumn{2}{|c|}{ Gulati and Saini } & \multicolumn{2}{|c|}{ Himanshu and Sen } & \multicolumn{2}{|c|}{ Dreze and Khera } \\
\hline & $2004 / 05$ & $2011 / 12 *$ & $2004 / 05$ & $2011 / 12$ & $2004 / 05$ & $2011 / 12$ & $2004 / 05$ & $2011 / 12$ \\
\hline Tripura & 47.8 & 24.8 & & 19.2 & 45.4 & 19.3 & & \\
\hline Uttar Pradesh & 84.9 & 60.4 & 58 & 47.9 & 83.7 & 54.3 & 58 & 57.6 \\
\hline Uttaranchal & 38.1 & 24.8 & 59.4 & 30 & 32.5 & 18.6 & 59.4 & 34.9 \\
\hline West Bengal & 85.9 & 61.7 & 80.6 & 69.4 & 85 & 56.8 & 80.6 & 65.3 \\
\hline All India & 58.6 & 43.1 & 54 & 46.7 & 54 & 34.6 & 54 & 41.7 \\
\hline
\end{tabular}

Note: Diversion or leakage of food grain from the PDS is defined as the amount of PDS food grain purchased by beneficiaries as a percentage of the total food grains allocated to FPSs for distribution**. Thus, PDS "leakages" refer to the share of PDS food grains released by the Food Corporation of India (FCI) which don't reach their intended consumers.

Sources: Gulati, Ashok and Shweta Sahni (2015). "Leakages from Public Distribution System (PDS) and the Way Forward".http://icrier.org/ pdf/Working_Paper_294.pdf

Dreze, Jean and Reetika Khera (2015). “Understanding Leakages in the Public Distribution System”. Economic and Political Weekly, Vol. 50(7) Himanshu, and A. Sen (2013). “In-Kind Food Transfers - I: Impact on Poverty". Economic and Political Weekly, Vol. 48(45-46): 46-58.

\footnotetext{
** Official offtake data for PDS(BPL, APL, AAY) offtake from Department of Food and Public Distribution -->http://dfpd.nic.in/?q=node/829. PDS Offtake calculated from NSSO Rounds.
} 




\section{Development}

Education

Education

\section{Health}

\section{Jobs}

\section{Inclusion}

Infrastructure

Growth

Growth

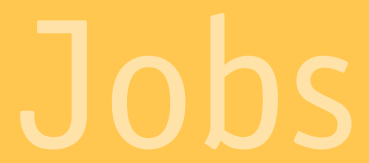

Urbanization

Urbanization

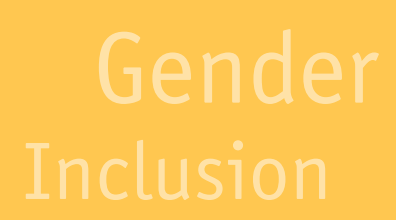

Education

Development

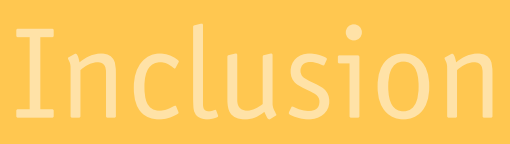

Poverty

Education

Jobs

Jobs

Health

Development

Health

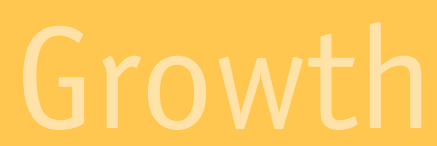

Education

Urbanization

Health Urbanization Jobs

Development

Education

Jobs

Gender

Health Poverty

Inclusion

Health

Infrastructure Growth

Urbanization Gender

Education

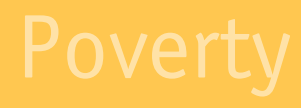

Inclusion 